\title{
Virology, DNA Viruses, Polyomavirus
}

National Cancer Institute

\section{Source}

National Cancer Institute. Virology, DNA Viruses, Polyomavirus. NCI Thesaurus. Code C19118.

The study of polyoma viruses and the diseases that they cause. 